\title{
The associations between lying with \\ Physical and Mental health statute students at University of Shahrekord, Iran
}

\author{
Research Article
}

\section{Mansoureh Kiani Dehkordi ${ }^{1,2}$, Ali Nazeri Astaneh ${ }^{3}$, Nayereh Abdali ${ }^{4}$ Freshteh Kiyani $^{4}$, Mostafa Madmoli ${ }^{5}$, Mansoor Khaledi ${ }^{6}$, Masoud Lotfizadeh ${ }^{7^{*}}$}

\author{
1. Psychotherapy Section (Unit), Department of Psychiatry, Tehran University of Medical Sciences, Tehran, Iran \\ 2. Psychosis Research Centre, University of Social Welfare and Rehabilitation Sciences, Tehran, Iran \\ 3. Associate Professor of Psychiatry, Psychosis Research Centre, \\ University of Social Welfare and Rehabilitation Science, Tehran, Iran \\ 4. BSc Public Health, Shahrekord University of Medical Sciences, Shahrekord, Iran \\ 5. Emergency Medical Technician, Gerash University of Medical Sciences, Gerash, Iran \\ 6. MS.c. in Medical Microbiology, Department of Microbiology and Immunology, \\ Shahrekord University of Medical Sciences, Shahrekord, Iran \\ 7. Associate professor, Social Determinants of Health Research Centre, \\ Shahrekord University of Medical Sciences, Shahrekord, Iran
}

\begin{abstract}
Background: Lying is a common phenomenon and one of the causes of insecurity in social relations. Considering the importance of this behavior in creating insecure relations in society, this study aimed to investigate the associations between lying with physical and mental health statute of university students. Methods: This crosssectional (descriptive-analytic) study investigated 651 students at various universities in Shahrekord, Iran. The data collection tool was a questionnaire consisting of three parts: demographic characteristics, general health questionnaire, and a researcher-made questionnaire of lying, completed by students. Data were analyzed using central tendency and distribution indices. Results: Results showed that a significant relationship between sex with physical diseases, and social functioning with depression $(\mathrm{p}=0.0001)$. Also, there was a statistically significant relationship between personal and social lies with physical health, anxiety and depression $(\mathrm{p}=0.0001)$, and between family income levels and personal-familial lies. In addition, data analyses indicated that a significant difference between personal and social lies with gender $(\mathrm{p}=0.0001)$, but no significant difference with age categories. Conclusion: In nutshell, it is recommended that more attention be paid to the phenomenon of lying, in order to use these results in better management of anxiety and depressive disorders, and their harmful effects on the health system and economics of the country. This issue requires further attention and study.
\end{abstract}

Keywords: Lying, Physical Health, Mental Health, Univer sity student.

\section{Introduction}

Traditionally, lying is a common ubiquitous form of social behavior that all people, at some time, engage in $(1,2)$. Lying is a statement that contradicts with reality and a liar is someone who tells the opposite of reality; changes the truth and distorts it is a lie, and the teller is a liar $(3,4)$. Lying is a disorder that can lead to a social crisis and may cause many harms to the individual and society, make the person susceptible to anxiety and fear, which itself threatens physical and mental health of individuals. This antisocial behavior may exist in any society according to the environmental and cultural conditions, and impose many harmful effects on the health of the individual and society, all of which affect the efficiency of individuals in different

*Corresponding Author:

Masoud Lotfizadeh,

Associate professor,

Social Determinants of Health Research Center,

Shahrekord University of Medical Sciences,

Shahrekord, Iran.

Email: masoudlotfi235@gmail.com systems, in terms of creating safe work relations and economical aspects, and impose hidden devastating effects on the economic system of countries and the health system of society (5).

However, as indicated in the statistics on the currency of physical and mental disorders in many countries, especially the developing countries such as Iran, the physical and mental health status are at a critical level. As defined by the World Health Organization, health includes physical, mental, and social wellbeing, not just lack of disease or disability (6); so a liar threatens his health by the fear of disclosure and consequences of lying. All factors affecting lying create a kind of fear and anxiety in the liar and influence their mental and physical health, in fact, lies themselves have a kind of social interactions (7).

Little attention is paid to the physical and mental aspects of health in many developing countries, due to focusing on other health priorities such as epidemics of infectious diseases in the past and chronic diseases in the present era (8). As university students take their first steps as adults after exit-ing adolescence, they adapt to a diverse environment, expanded personal relationships, 
scholastic tests that are different from those of the past middle and high school years, autonomy, and a transition period between heteronomy (9). Thus, this research aimed to identify the associations between lying with physical and mental health statute among college students.

\section{Materials and Methods}

The present cross-sectional (descriptive-analytic) study was conducted at nine different universities of Shahrekord, Iran (including University of Medical Sciences, Shahrekord University, Islamic Azad University, Payam Noor University, Farhangian University, University of Applied Science and Technology, non-profit University, and Technical School of girls and boys) on 651 students from bachelor to master degree (318 males, 333 female) during 2015 academic year.

After obtaining the approval of the University Research Council (code No.: 942116901) and Ethics Committee, the researchers and coinvestigators started data collection. To this aim, the researchers explained the process to the students and obtained their informed consents.

The data collection tool included three parts: I) demographic characteristics (7 questions); II) general health questionnaire (GHQ); and III) researcher-made questionnaire of lying (40 questions). GHQ consists of four sub-tests; 1) questions 1 to 7 assessed physical symptoms; 2) questions 8 to 14 anxiety and insomnia; 3 ) questions 15 to 21 social function abnormalities; and 4) questions 22 to 28 depression. The validity and reliability of this study have been reported desirable in various studies (10).

In this study, based on the article by Noorbala et al. (2000), scores $<23$ was considered healthy subjects and $>24$ suspected of disorder (11). The reliability of the researcher-designed questionnaire of lying was assessed by a number of experts (psychologist and social health) and its validity was evaluated on 30 male and female students, reporting a Cronbach's alpha coefficient of 0.85 . In this questionnaire, the answers to the questions had three options: (never $=0$, sometimes $=$ 1 , often =2). Questions of the lying questionnaire had two social and personal-familial categories, such that half of the questions were in the social domain and the other half in the personal-familial domain.

The researchers used "never, sometimes and often" in the pilot study to classify lies: never with a score of 27 or more, sometimes with a score of 13-26, and often with a score of 0-12. Data was collected using the mentioned questionnaire by the researcher referring to various universities Shahrekord in person, providing complete explanations to participants, and obtaining consent of the participants in the study, then the incomplete questionnaires were excluded from the study.

To analyze the data, firstly descriptive statistics methods including central tendency and distribution indices were used to describe the study variables. The data were described using mean, standard deviation, and percentile, and then analyzed by Pearson productmoment correlation and Chi-square tests to find the relationship between laying with physical and mental health data. The analyses were performed using SPSS 22 software at significance level of less than 0.05 .

The inclusion criteria for recruitment into the study included all students studying at the mentioned universities in the academic year 2015, and the exclusion criteria was dropping out of education, graduation, absence from university during the study period, incomplete questionnaires, and willingness to leave the study.

\section{Results}

Table 1 shows demographic information of the students.

Table 1: Demographic information of the students

\begin{tabular}{|c|c|c|c|c|c|c|c|c|c|}
\hline \multirow{2}{*}{$\begin{array}{c}\text { Students } \\
\text { Characteristics }\end{array}$} & \multirow{2}{*}{$\begin{array}{c}\text { Age } \\
\text { (years) }\end{array}$} & \multicolumn{4}{|c|}{$\begin{array}{c}\text { Family income } \\
\text { (million Tomans), \% }\end{array}$} & \multicolumn{2}{c|}{$\begin{array}{c}\text { Residential status } \\
\text { (\%) }\end{array}$} & \multicolumn{2}{c|}{$\begin{array}{c}\text { Living place } \\
\text { (\%) }\end{array}$} \\
\cline { 3 - 10 } & & $1.5-2$ & $1-1.5$ & $>2$ & $<1$ & native & Non-native & urban & rural \\
\hline Average & $21.4 \pm 2.9$ & 42.9 & 28.6 & 19 & 9.5 & 60.5 & 39.5 & 89.9 & 10.1 \\
\hline
\end{tabular}

Results showed that a significant relationship between sex with physical diseases, and social functioning with depression $(p=0.0001)$. There was no statistical relationship between the family income levels with originality of students and the general health (Table 2).

Table 2. Relationship of demographic characteristics with general health

\begin{tabular}{|c|c|c|c|c|c|}
\hline Demographic & Income & Residential status & Living place & University & Sex \\
\hline GHQ & P value & P value & P value & P value & P value \\
\hline Physical health & 0.776 & 0.546 & 0.558 & 0.102 & 0.000 \\
\hline Anxiety & 0.211 & 0.188 & 0.864 & 0.158 & 0.123 \\
\hline Social function & 0.385 & 0.435 & 0.005 & 0.042 & 0.001 \\
\hline Depression & 0.287 & 0.206 & 0.369 & 0.148 & 0.030 \\
\hline
\end{tabular}

${ }^{1}$ General health questionnaire

In addition, data analyses indicated that a significant difference between personal and social lies with gender $(p=0.0001)$, but no significant difference with age categories (Table 3$)$. 
Table 3: The relationship of lying with gender and age groups

\begin{tabular}{|l|c|c|}
\hline \multirow{2}{*}{ Lying } & Sex & Age categories \\
\cline { 2 - 3 } & P value & P value \\
\hline Personal-familial & 0.0001 & 0.279 \\
\hline Social & 0.001 & 0.925 \\
\hline
\end{tabular}

Here was no statistically significant relationship between social lying and demographic factors, or between personal and social lies and social dysfunction, but there was a statistically significant relationship between personal and social lies with physical health, anxiety and depression $(\mathrm{p}=.0001)$, and between family income levels and personal-familial lies (Table 4).

Table 4. The relationship of types of lies with general health dimensions and demographic characteristics

\begin{tabular}{|c|c|c|c|c|}
\hline Types of lie & Demographic characteristics & P value & GHQ & P value \\
\hline \multirow{4}{*}{ Social lies } & Income level & 0.298 & Physical health & 0.001 \\
\cline { 2 - 5 } & Residential status & 0.101 & Insomnia-anxiety & 0.000 \\
\cline { 2 - 5 } & Living place & 0.282 & Social function & 0.448 \\
\cline { 2 - 5 } & University & 0.161 & Depression & 0.000 \\
\hline \multirow{3}{*}{ Personal-familial lies } & Income level & 0.043 & Physical health & 0.001 \\
\cline { 2 - 5 } & residential status & 0.937 & Insomnia-anxiety & 0.000 \\
\cline { 2 - 5 } & Address & 0.492 & Social function & 0.212 \\
\cline { 2 - 5 } & Depression & 0.166 & Depression & 0.000 \\
\hline
\end{tabular}

\section{Discussion}

Despite many efforts, unfortunately no studies have addressed lying in Iran and there were only few studies available, which were not completely relevant to the subject of the present study and have not evaluated the impact of these behaviors on the health of individuals.

As the findings of this study indicated, statistically significant relationship between gender and personal with social lies, as boys were lying more than girls. Magda also points to the gender difference in the level of lying in his study, and states that the prevalence of lying is higher in boys than girls (12), but Talwar et al. (2002) observed no significant associations between gender and lying in his study on 54 children. Since lying in childhood is normal to a certain age (13), generalizability of Magda's study and our results can be considered more acceptable regarding larger sample size of this study (14).

Based on our results personal lying was associated with income level, and lying increased with a rise in income level. It has also been mentioned in Hample research (1980) that there was a relationship between lying and income level, and 3 of 4 lies were due to the high socioeconomic level (15).

However, this study, which aimed to investigate the associations between lying and physical and mental health. Results showed significant association of social and personal lies with anxiety, depression, and physical health; in other words, they have a kind of mutual relationship. In 2008 Hurkens and Kartik (16), argued that as long as a person is lying, he thinks about the extent to which the changes and achievements of lying will benefit him. In fact, this anxiety and concern in the person caused by lying can affect his health. Hample (1980) states that in the same conditions, lies can be both harmful and beneficial. Hancock et al. (2007) has also pointed to the social interactions of lying. Also, the results of the Genzi's study showed that people are not only concerned about the benefits of lying, but also about the harms the lie may bring to them (17), so these worries make them susceptible to anxiety and depression and can ultimately endanger the physical and mental health of the individual.

In the present study, there was no significant relationship between age groups and lying, while Hancock et al. (2007) observed that young men and women are more likely to lie than older ones (17); this difference may be due to the fact that in this study only young individuals have been studied with a similar age range and is thus different from other studies. A line with the results present study, Talwar et al. (2002) results referred to the significant effect of age and stated that children older than three years told more lies than other children (13). Thus, it is recommended that this study be repeated in future on different age groups and occupations, in order to assess the impact of age and social class more accurately. In addition, it is recommended to conduct retrospective studies for better understanding of causes of lying and effective factors in causing physical and psychological disorders.

\section{Conclusion}

The results of this study can be effective in increasing the awareness on the impact of lying on physical and psychological health and help psychologists, physicians, and psychiatrists in order to accelerate recovery of patients with anxiety and depressive disorders, as well as other physical diseases. The results of this study can also be used in proper training for implementation of mutual confident and integrated relations in families to add its strength and effectively reduce the number of divorces and improve children's education.

Anxiety and depression have a high impact on young people's lying. In the future, these young people become active working force in the society, so organizational managers can use the results of this study 
to increase safe occupational and social relationships, reduce the physical and psychological effects, and indirectly reduce the amount of expenses imposed on the health system and economics of the countries.

\section{Acknowledgements}

The authors would like to thank the ViceChancellor of Research Deputy in Shahrekord University of Medical Sciences for approving and funding the research project (No. 1743) and all students participating in the study.

\section{Conflict of interest}

There are no conflicts of interest in this article.

\section{References}

1. Vrij A. Detecting Lies and Deceit: The Psychology of Lying and Implications for Professional Practice. (Wiley Series on the Psychology of Crime, Policing and Law). 2002; 3(5): 22-28

2. Grubin D. Commentary: Getting at the truth about pathological lying. Journal of the American Academy of Psychiatry and the Law Online. 2005 Sep 1;33(3):350-3.

3. Sadr R. Lie. Center for Islamic Publications Bureau. 1999

4. Atrak H. Means of then condition lie. Journal of Philosophical Research of Tabriz University, 2013; 7(2): 1-25.

5. World Health Organization. Promoting mental health: concepts, emerging evidence, practice: a report of the World Health Organization, Department of Mental Health and Substance Abuse in collaboration with the Victorian Health Promotion Foundation and the University of Melbourne. 2005.

6. Biglar M, Hayati Y, Rahmani H, Rajabnezhad Z, Dargahi H. Study of general health among Tehran University Of Medical Sciences hospital's administrators. Journal of Payavard Salamat. 2014 May 15;8(1):13-24.

7. Porter S, ten Brinke L. The truth about lies: What works in detecting high $\square$ stakes deception? Legal and criminological Psychology. 2010 Feb;15(1):57-
75.

8. Manchri H, Sanagoo A, Jouybari L, Sabzi Z, Jafari $Y$. The relationship between mental health status with academic performance and demographic factors among students of university of medical sciences. Journal of Nursing and Midwifery Sciences. 2017 May 15;4(1):8-13.

9. Han HW, Lee YC. The relationship among participation of dance sport, body image and mental health for university students. Journal of Korean Physical Education Association for Girl and Women. 2006;20(20):109-20.

10. Bayani AA, Goodarzi H, Koochaki AM. The association between psychological well-being and mental health of Students University of Azad Shahr city. Science and Research in Psychology Islamic Azad University of Khorasgan. 2008; 36(7): 153164.

11. Noorbala AA, Bagheri Yazdi SA, Moham- mad K. The validation of general health questionnaire- 28 as a psychiatric screening tool. Hakim 2009; 11(4): 4753

12. Stouthamer-Loeber M. Lying as a problem behavior in children: A review. Clinical Psychology Review. 1986 Jan 1;6(4):267-89.

13. Talwar V, Lee K. Development of lying to conceal a transgression: Children's control of expressive behaviour during verbal deception. International Journal of Behavioral Development. 2002 Sep;26 (5):436-44.

14. Stouthamer-Loeber M. Lying as a problem behavior in children: A review. Clinical Psychology Review. 1986 Jan 1;6(4):267-89.

15. Hample D. Purposes and effects of lying. Southern speech communication journal. 1980 Nov 1;46 (1):33-47.

16. Hurkens S, Kartik N. Would I lie to you? On social preferences and lying aversion. Experimental Economics. 2009 Jun 1;12(2):180-92.

17. Hancock JT, Toma C, Ellison N. The truth about lying in online dating profiles. InProceedings of the SIGCHI conference on Human factors in computing systems 2007 Apr 29; 2(6): 449-452. 